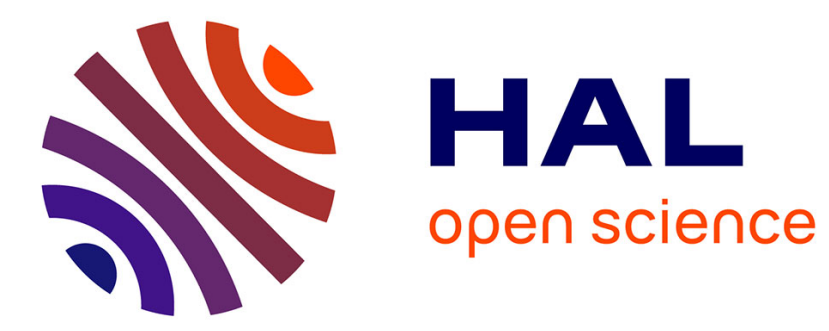

\title{
Sensorless second order sliding mode observer for induction motor
}

Sebastien Solvar, Vu Le, Malek Ghanes, Jean-Pierre Barbot, Gaëtan Santomenna

\section{- To cite this version:}

Sebastien Solvar, Vu Le, Malek Ghanes, Jean-Pierre Barbot, Gaëtan Santomenna. Sensorless second order sliding mode observer for induction motor. IEEE Control Conference Application, Nov 2010, Yokohama, Japan. pp.6. inria-00531067

\section{HAL Id: inria-00531067 https://hal.inria.fr/inria-00531067}

Submitted on 2 Nov 2010

HAL is a multi-disciplinary open access archive for the deposit and dissemination of scientific research documents, whether they are published or not. The documents may come from teaching and research institutions in France or abroad, or from public or private research centers.
L'archive ouverte pluridisciplinaire HAL, est destinée au dépôt et à la diffusion de documents scientifiques de niveau recherche, publiés ou non, émanant des établissements d'enseignement et de recherche français ou étrangers, des laboratoires publics ou privés. 


\title{
Sensorless second order sliding mode observer for induction motor
}

\author{
S. SOLVAR, V. LE, M. GHANES, J.P. BARBOT and G. SANTOMENNA
}

\begin{abstract}
In this paper, a second order sliding mode observer for the induction motor without mechanical sensor is presented. This observer converges in finite time and is robust to the variation of parameters. Using Matlab/Simulink, the simulation results show the performance of the proposed observer. Furthermore, an industrial application is presented in order to highlight the technological interest of the proposed method and also show the difficulties due to real time computation constraints.
\end{abstract}

Index Terms - Induction Motor, Sensorless, Observer, Sliding mode, Super Twisting

\section{INTRODUCTION}

Nowadays Induction Motors (IMs) have replaced DC motors in the industrial application. There are many different ways to drive an induction motor. The differences between them are the performance of motor and the cost of implementation. The voltage over frequency method is the simplest method. This is a basic scalar control which imposes a constant relation between stator voltage and frequency. It is normally used without speed sensor. However, this control has not a good accuracy in speed and torque response because the flux and the torque are not controlled directly [8]. Contrarily, in the vector control which is based on relations valid for dynamic states, magnitude and instantaneous position of voltage, current and flux are controlled. This control allows to have a good motor's performance with respect to permanent state and dynamic state behavior. But, in the vector control the mechanical speed and the flux are needed. For this reason, in the recent years high performance sensorless induction motor drivers have attracted a great attention in industrial applications due to theirs advantages such as low cost, low maintenance, high reliability etc. The sensorless control helps to reduce the cost and resolves installing problem in many applications: lack of place, dangerous environment. Present effort are devoted to improve the performance of observer at low speed [16] and to develop a robust observer against perturbations and variation of parameters.

Several methods have been proposed to estimate speed and flux of IM such as: Luenberger observer [1] and Kalman filter [14], high gain and adaptive observers [6], [16] neural networks and signal injection [7] and sliding mode observer [15] etc. Compared with other observers, sliding mode

S. SOLVAR, M. GHANES and J.P. BARBOT are with ECS/ENSEA, 6 Avenue du Ponceau, 95014 Cergy-Pontoise, France.

V.T.H LE is with SUPELEC, 3 rue Joliot-Curie 91192, Gif sur Yvette, France.

J.P. BARBOT is also with the EPI-ALIEN-INRIA.

G. SANTOMENNA and S. SOLVAR are with GS Maintenance, 16 rue Henri Schneider, 77430 Champagne sur Seine, France. technics [5] has attractive advantages of robustness to disturbances and insensitivity to variation of parameters when the sliding mode happens. However, the chattering behavior, that is inherent in standard sliding mode techniques, is often an obstacle for practical application if neglected. HigherOrder Sliding Mode [3] is one of the solutions which does not compromise robustness and avoid filtering estimation considered by other methods. In this paper, a new sensorless second sliding mode observer is proposed to estimates flux and speed of $I M$ under unknown load torque. Firstly the observer is designed in continuous time. Thereafter, the work consists to show how to get a sliding mode observer under sampling in order to implement it on an experimental set-up for an industrial application. Here the sliding mode observer is over sampled in order to by pass the difficulties due to slow data acquisition. This paper is organized as follows: the section II recalls the IM model. In section III the observabilty of the $I M$ is presented. After that the section IV proposes a second order sliding mode observer which is applied for IM. In sections $\mathrm{V}$ and $\mathrm{VI}$, the simulation and experimentation results are shown to confirm the good performance of the second order sliding mode observer. Some conclusions and remarks are drawn in section VII.

\section{IM PER-UNit MOdEL}

In order to construct the proposed observer for an industrial application, the $I M$ model given by [9] in the fixed $(\alpha, \beta)$ frame is rewritten under the following Per-Unit (p.u.) equations:

$$
\left\{\begin{array}{l}
\dot{x}_{1}=\gamma \cdot x_{1}+\theta \cdot\left(b \cdot x_{3}+c \cdot x_{5} x_{4}\right)+\xi \cdot v_{1} \\
\dot{x}_{2}=\gamma \cdot x_{2}+\theta \cdot\left(b \cdot x_{4}-c \cdot x_{5} x_{3}\right)+\xi \cdot v_{2} \\
\dot{x}_{3}=a \cdot x_{1}-b \cdot x_{3}-c \cdot x_{5} \cdot x_{4} \\
\dot{x}_{4}=a \cdot x_{2}-b \cdot x_{4}+c \cdot x_{5} \cdot x_{3} \\
\dot{x}_{5}=h \cdot\left(x_{3} \cdot x_{2}-x_{4} \cdot x_{1}\right)-d \cdot x_{5}-e \cdot T_{l}
\end{array}\right.
$$

with:

$x_{1}=\frac{i_{s \alpha}}{I_{r e f}}, x_{2}=\frac{i_{s \beta}}{I_{r e f}}, x_{3}=\frac{\omega_{s r e f} \cdot \phi_{r \alpha}}{V_{r e f}}$,

$x_{4}=\frac{\omega_{s r e f} \cdot \phi_{r \beta}}{V_{r e f}}, x_{5}=\frac{p \cdot \Omega}{\omega_{s r e f}}, \sigma=1-\frac{M_{s r}^{2}}{L_{s} \cdot L_{r}}$,

$\gamma=\frac{R_{s} \cdot L_{r}^{2}+R_{r} \cdot M_{s r}^{2}}{\sigma \cdot L_{s} \cdot L_{r}^{2}}, T_{r}=\frac{L_{r}}{R_{r}}, K=\frac{M_{s r}}{\sigma \cdot L_{s} \cdot L_{r}}$,

$a=\frac{M_{s} r \cdot I_{r e f} \cdot \omega_{r e f}}{T_{r} \cdot V_{r e f}}, b=\frac{1}{T_{r}}, c=\omega_{r e f}$,

$d=\frac{f_{v}}{J}, e=\frac{p}{J \cdot \omega_{r e f}}, h=\frac{p^{2} \cdot M_{s r} \cdot I_{r e f} \cdot V_{r e f}}{J \cdot \omega_{r e f}^{2} \cdot L_{r}}$,

$\theta=\frac{K \cdot V_{\text {ref }}}{I_{\text {ref }} \cdot \omega_{\text {ref }}}, \quad \xi=\frac{V_{\text {ref }}}{\sigma \cdot L_{s} \cdot I_{\text {ref }}}$

and

$i_{s \alpha}, i_{s \beta}, \phi_{r \alpha}, \phi_{r \beta}, \Omega$ are respectively the stator currents, the rotor fluxes and the speed. $I_{r e f}, V_{r e f}$, are the maximal values of stator current and voltage. $\omega_{\text {sref }}$ is the nominal stator pulsation. $R_{s}$ and $R_{r}$ are the stator and rotor resistance. $L_{s}$ and $L_{r}$ are the stator and rotor inductance. $M_{s r}$ is mutual 
inductance. $p$ is the number pairs of pole. $J$ is motor inertia and $f_{v}$ the viscous friction coefficient. $T_{l}$ is the load torque. Notice that for the sake of homogeneity, hereafter the simulation and experimental results will be given in per-unit (p.u.).

\section{BRIEF RECALL OF IM OBSERVABILTY}

It is shown in ([10],[16]) that the IM observability cannot be established in the particular case when the fluxes $\phi_{r \alpha}$, $\phi_{r \beta}$ and the speed $\Omega$ are constant even if we use the higher derivatives of currents. This is a sufficient and necessary condition for lost of observability. This operating case match to the following physically interpretation :

1) when the fluxes are constant $\left(\dot{\phi}_{r \alpha}=\dot{\phi}_{r \beta}=0\right)$, or equivalently, the stator pulsation voltage is zero $\left(\omega_{s}=0\right)$, it implies that: $p \Omega+\frac{R_{r} T_{e}}{p \phi_{d}^{2}}=\omega_{s}=0$ or: $T_{e m}=-K \Omega$ where $T_{e m}$ is the electromagnetic torque, $K=\frac{p^{2} \phi_{d}^{2}}{R_{r}}$ and $\phi_{d}^{2}=\sqrt{\phi_{r \alpha}^{2}+\phi_{r \beta}^{2}}$.

$2)$ if the speed motor is constant; thus: $T_{e m}=\left(f_{v} \Omega+\right.$ $\left.T_{l}\right)=-K \Omega$. This last equation defines the unobservability curve in the map $\left(T_{l}, \Omega\right)$ with $M=\frac{p^{2} \phi_{d}^{2}}{R_{r}}+f_{v}$ (Figure 1).

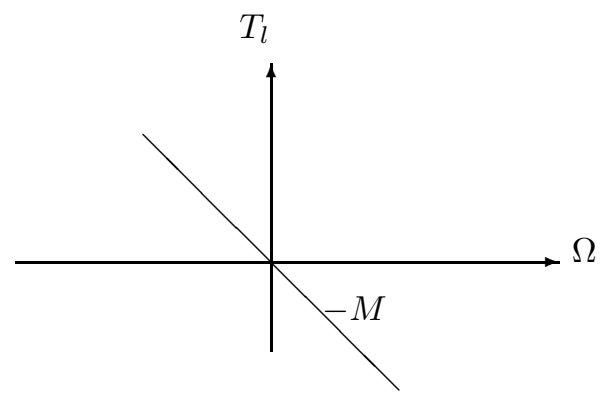

Fig. 1. Unobservability curve in the map $\left(T_{l}, \Omega\right)$.

Obviously, the observability is lost gradually when we approach this unobservability curve.

\section{SECOND ORDER SLIDING MODE OBSERVER DESIGN}

\section{A. Recall on sliding mode observer}

The sliding mode technique is used at first in control theory, but in the recent years sliding mode is presented such as a good observer for many applications [2], [11], [13]. Considering a system:

$$
\left\{\begin{aligned}
\dot{x}_{1} & =x_{2} \\
\dot{x}_{2} & =x_{3} \\
& \vdots \\
\dot{x}_{n} & =f\left(x_{1}, \cdots, x_{2}\right) \\
y & =x_{1}
\end{aligned}\right.
$$

To this system, a second order sliding mode observer is designed in the following way:

$$
\left\{\begin{array}{c}
\dot{\hat{x}}_{1}=\tilde{x}_{2}+\lambda_{1} \cdot\left|x_{1}-\hat{x}_{1}\right|^{\frac{1}{2}} \cdot \operatorname{sign}\left(x_{1}-\hat{x}_{1}\right) \\
\dot{\tilde{x}}_{2}=\alpha_{1} \cdot \operatorname{sign}\left(x_{1}-\hat{x}_{1}\right) \\
\dot{\hat{x}}_{2}=E_{1} \cdot\left[\tilde{x}_{3}+\lambda_{2} \cdot\left|\tilde{x}_{2}-\hat{x}_{2}\right|^{\frac{1}{2}} \cdot \operatorname{sign}\left(\tilde{x}_{2}-\hat{x}_{2}\right)\right] \\
\vdots \\
\dot{\tilde{x}}_{n}=E_{n-2} \cdot \alpha_{n-1} \cdot \operatorname{sign}\left(\tilde{x}_{n-1}-\hat{x}_{n-1}\right) \\
\dot{\hat{x}}_{n}=E_{n-1} \cdot\left[\tilde{\theta}+\lambda_{n} \cdot\left|\tilde{x}_{n}-\hat{x}_{n}\right|^{\frac{1}{2}} \cdot \operatorname{sign}\left(\tilde{x}_{n}-\hat{x}_{n}\right)\right] \\
\dot{\tilde{\theta}}^{=} E_{n-1} \cdot \alpha_{n} \cdot \operatorname{sign}\left(\tilde{x}_{n}-\hat{x}_{n}\right) \\
\text { with } E_{i}=\left\{\begin{array}{l}
1 \text { if } \tilde{x}_{i}-\hat{x}_{i}=0 \\
0 \text { if not }
\end{array}\right.
\end{array}\right.
$$

\section{B. Application for IM}

1) Continuous observer: Firstly, considering a change of variable like that:

$$
\left\{\begin{aligned}
z_{1} & =x_{1} \\
z_{2} & =x_{2} \\
z_{3} & =b \cdot x_{3}+c \cdot x_{5} x_{4} \\
z_{4} & =b \cdot x_{4}-c \cdot x_{5} x_{3} \\
z_{5} & =\dot{z}_{3} \\
z_{6} & =\dot{z}_{4}
\end{aligned}\right.
$$

From the IM model (1) and this change of variable (4), a dynamical system for (4) can be obtained as:

$$
\begin{cases}\dot{z}_{1} & =-\gamma \cdot z_{1}+\theta \cdot z_{3}+\xi \cdot v_{1} \\ \dot{z}_{2} & =-\gamma \cdot z_{2}+\theta \cdot z_{4}+\xi \cdot v_{2} \\ \dot{z}_{3} & =z_{5} \\ \dot{z}_{4} & =z_{6} \\ \dot{z}_{5} & =z_{7} \\ \dot{z}_{6} & =z_{8}\end{cases}
$$

Now by applying the second order sliding mode observer (3) recalled on the section (IV-A) for system (5) we get an observer in the following way:

$$
\left\{\begin{aligned}
\dot{\tilde{z}}_{1}=\theta \cdot \tilde{z}_{3}-\gamma \cdot z_{1}+\xi \cdot v_{1}+\lambda_{1} \cdot\left|e_{1}\right|^{\frac{1}{2}} \cdot \operatorname{sign}\left(e_{1}\right) \\
\dot{\tilde{z}}_{3}=\alpha_{1} \cdot \operatorname{sign}\left(e_{1}\right) \\
\dot{\tilde{z}}_{2}=\theta \cdot \tilde{z}_{4}-\gamma \cdot z_{2}+\xi \cdot v_{2}+\lambda_{2} \cdot\left|e_{2}\right|^{\frac{1}{2}} \cdot \operatorname{sign}\left(e_{2}\right) \\
\dot{\tilde{z}}_{4}=\alpha_{2} \cdot \operatorname{sign}\left(e_{2}\right) \\
\dot{\hat{z}}_{3}=E_{1} \cdot E_{2} \cdot\left(\tilde{z}_{5}+\lambda_{3} \cdot\left|e_{3}\right|^{\frac{1}{2}} \cdot \operatorname{sign}\left(e_{3}\right)\right) \\
\dot{\tilde{z}}_{5}=E_{1} \cdot E_{2} \cdot \alpha_{3} \cdot \operatorname{sign}\left(e_{3}\right) \\
\dot{\tilde{z}}_{4}=E_{1} \cdot E_{2} \cdot\left(\tilde{z}_{6}+\lambda_{4} \cdot\left|e_{4}\right|^{\frac{1}{2}} \cdot \operatorname{sign}\left(e_{4}\right)\right) \\
\dot{\tilde{z}}_{6}=E_{1} \cdot E_{2} \cdot \alpha_{4} \cdot \operatorname{sign}\left(e_{4}\right) \\
\dot{\tilde{z}}_{5}=E_{1} \cdot E_{2} \cdot E_{3} \cdot E_{4} \cdot\left(\tilde{z}_{7}+\lambda_{5} \cdot\left|e_{5}\right|^{\frac{1}{2}} \cdot \operatorname{sign}\left(e_{5}\right)\right) \\
\dot{\tilde{z}}_{7}=E_{1} \cdot E_{2} \cdot E_{3} \cdot E_{4} \cdot \alpha_{5} \cdot \operatorname{sign}\left(e_{5}\right) \\
\dot{\tilde{z}}_{6}=E_{1} \cdot E_{2} \cdot E_{3} \cdot E_{4} \cdot\left(\tilde{z}_{8}+\lambda_{3} \cdot\left|e_{6}\right|^{\frac{1}{2}} \cdot \operatorname{sign}\left(e_{6}\right)\right) \\
\dot{\tilde{z}}_{8}=E_{1} \cdot E_{2} \cdot E_{3} \cdot E_{4} \cdot \alpha_{6} \cdot \operatorname{sign}\left(e_{6}\right) \\
\quad \text { with } E_{i}\left\{\begin{array}{l}
1 \text { if } e_{i}=\tilde{z}_{i}-\hat{z}_{i}=0 \\
0 \text { if not }
\end{array}\right.
\end{aligned}\right.
$$

The functions $E_{i}$ ensure that the next steps errors do not escape too far before one has the convergent of the last step error.

By choosing the gains $\alpha_{i}, \lambda_{i}$ which respect to the reachability 
condition of the Super Twisting algorithm [2], [11], [12] for example: $\alpha_{1}>z_{5 \max }, \lambda_{1}>4 \cdot z_{5 \max } \cdot \frac{\alpha_{1}+z_{5 \max }}{\alpha_{1}-z_{5 \max }}$, we get $e_{1}=e_{2}=\ldots=e_{6}=0$, ie $\hat{z}_{1}=z_{1}, \hat{z}_{2}=z_{2} \ldots \hat{z}_{6}=z_{6}$ after some finite time $\mathrm{T}$.

To find out the estimated speed and flux, equations (4) are solved as follows.

One has $z_{3}=b \cdot x_{3}+c \cdot x_{5} \cdot x_{4}$, i.e.,

$$
x_{3}=\frac{1}{b} \cdot\left(z_{3}-c \cdot x_{5} \cdot x_{4}\right)
$$

Furthermore, one has $x_{4}=\frac{1}{b} \cdot\left(z_{4}+c \cdot x_{5} \cdot x_{3}\right)$. If one replaces $x_{3}$ by equation (7) one obtains:

$$
x_{4}=\frac{z_{4}+\frac{c}{b} \cdot z_{3} \cdot x_{5}}{b+\frac{c^{2} \cdot x_{5}^{2}}{b}}
$$

In the similar way, we get:

$$
x_{3}=\frac{z_{3}-\frac{c}{b} \cdot z_{4} \cdot x_{5}}{b+\frac{c^{2} \cdot x_{5}^{2}}{b}}
$$

If one derives the equation (7) we obtain:

$$
z_{5}=b \cdot\left(-z_{3}+a \cdot x_{1}\right)+c \cdot \dot{x}_{5} \cdot x_{4}+c \cdot x_{5} \cdot\left(-z_{4}+a \cdot x_{2}\right)
$$

In the similar way, we have:

$$
z_{6}=b \cdot\left(-z_{4}+a \cdot x_{2}\right)-c \cdot \dot{x}_{5} \cdot x_{3}-c \cdot x_{5} \cdot\left(-z_{3}+a \cdot x_{1}\right)
$$

So one has 4 equations $(8,9,10,11)$ with 4 unknowns $x_{3}$, $x_{4}, x_{5}$ and $\dot{x}_{5}$. Solving these equations we can find out the estimated speed and rotor fluxes.

To estimate the rotor speed we can add a following hypothesis: the speed is constant in comparison with the variation of stator current. From this hypothesis and equations (4) one can estimate the speed and the rotor flux.

$$
\begin{gathered}
\hat{x}_{5}=\frac{\hat{z}_{5}+b \cdot \hat{z}_{3}-b \cdot a \cdot \hat{z}_{1}}{-c \cdot z_{4}+c \cdot a \cdot \hat{z}_{2}} \\
\hat{\phi}_{r \alpha}=\frac{\hat{z}_{3}-\frac{c \cdot \hat{x}_{5} \cdot \hat{z}_{4}}{b}}{b+\frac{c^{2} \cdot \hat{x}_{5}^{2}}{b}} \\
\hat{\phi}_{r \beta}=\frac{\hat{z}_{4}+\frac{c \cdot \hat{x}_{5} \cdot \hat{z}_{3}}{b}}{b+\frac{c^{2} \cdot \hat{x}_{5}^{2}}{b}}
\end{gathered}
$$

The designed second order sliding mode has another advantage because one does not need to know the load torque to estimate the motor's speed.

2) Discrete Observer: For the industrial application in real time, the discrete observer is constructed. The explicit Euler's method is chosen to transform continuous observer to discrete observer. This is due to the simplicity of computation. Nevertheless in order to obtain the request precision this discretization is used $\mathrm{n}$ times, doing so the discretization error is in $n O\left(\left(\frac{T_{e}}{n}\right)^{2}\right)$ instead of $O\left(\left(\frac{T_{e}}{n}\right)^{2}\right)$ with $T_{e}$ is the data acquisition period. This method is performed in section (16).
Applying the explicit Euler's method for the second order sliding mode observer, the discrete observer is obtained:

$$
\begin{aligned}
& \left\{\begin{aligned}
\hat{z}_{1}(k) & =\hat{z}_{1}(k-1)+T_{e} \cdot\left(\theta \cdot \tilde{z}_{3}(k-1)-\gamma \cdot z_{1}(k-1)\right. \\
& +\xi \cdot v_{1}(k-1) \\
& \left.\left.+\lambda_{1} \cdot \mid e_{1}(k-1)\right)\left.\right|^{\frac{1}{2}} \cdot \operatorname{sign}\left(e_{1}(k-1)\right)\right) \\
\tilde{z}_{3}(k) & =\tilde{z}_{3}(k-1)+T_{e} \cdot \alpha_{1} \cdot \operatorname{sign}\left(e_{1}(k-1)\right) \\
\hat{z}_{2}(k) & =\hat{z}_{2}(k-1)+T_{e} \cdot\left(\theta \cdot \tilde{z}_{4}(k-1)-\gamma \cdot z_{2}(k-1)\right. \\
& +\xi \cdot v_{2}(k-1) \\
& \left.+\lambda_{2} \cdot\left|e_{2}(k-1)\right|^{\frac{1}{2}} \cdot \operatorname{sign}\left(e_{2}(k-1)\right)\right) \\
\tilde{z}_{4}(k) & =\tilde{z}_{4}(k-1)+T_{e} \cdot \alpha_{2} \cdot \operatorname{sign}\left(e_{2}(k-1)\right) \\
\hat{z}_{3}(k) & =\tilde{z}_{3}(k-1)+T_{e} \cdot E_{1} \cdot E_{2} \cdot\left(\tilde{z}_{5}(k-1)\right. \\
& \left.+\lambda_{3} \cdot\left|e_{3}(k-1)\right|^{\frac{1}{2}} \cdot \operatorname{sign}\left(e_{3}(k-1)\right)\right) \\
\tilde{z}_{5}(k) & =\tilde{z}_{5}(k-1)+T_{e} \cdot E_{1} \cdot E_{2} \cdot \alpha_{3} \cdot \operatorname{sign}\left(e_{3}(k-1)\right) \\
\hat{z}_{4}(k) & =\hat{z}_{4}(k-1)+T_{e} \cdot E_{1} \cdot E_{2} \cdot\left(\tilde{z}_{6}(k-1)\right. \\
& \left.+\lambda_{4} \cdot\left|e_{4}(k-1)\right|^{\frac{1}{2}} \cdot \operatorname{sign}\left(e_{4}(k-1)\right)\right) \\
\tilde{z}_{6}(k) & =\tilde{z}_{6}(k-1)+T_{e} \cdot E_{1} \cdot E_{2} \cdot \alpha_{4} \cdot \operatorname{sign}\left(e_{4}(k-1)\right) \\
\hat{z}_{5}(k) & =\hat{z}_{5}(k-1)+T_{e} \cdot E_{1} \cdot E_{2} \cdot E_{3} \cdot E_{4} \cdot\left(\tilde{z}_{7}(k-1)\right. \\
& \left.+\lambda_{5} \cdot\left|e_{5}(k-1)\right|^{\frac{1}{2}} \cdot \operatorname{sign}\left(e_{5}(k-1)\right)\right) \\
\tilde{z}_{7}(k) & =\tilde{z}_{7}(k-1) \\
& +T_{e} \cdot E_{1} \cdot E_{2} \cdot E_{3} \cdot E_{4} \cdot \alpha_{5} \cdot \operatorname{sign}\left(e_{5}(k-1)\right) \\
\hat{z}_{6}(k) & =\hat{z}_{6}(k-1)+T_{e} \cdot E_{1} \cdot E_{2} \cdot E_{3} \cdot E_{4} \cdot\left(\tilde{z}_{8}(k-1)\right. \\
& \left.+\lambda_{3} \cdot\left|e_{6}(k-1)\right|^{\frac{1}{2}} \cdot \operatorname{sign}\left(e_{6}(k-1)\right)\right) \\
\tilde{z}_{8}(k) & =\tilde{z}_{8}(k-1) \\
& +T_{e} \cdot E_{1} \cdot E_{2} \cdot E_{3} \cdot E_{4} \cdot \alpha_{6} \cdot \operatorname{sign}\left(e_{6}(k-1)\right) \\
&
\end{aligned}\right. \\
& \text { with } E_{i}\left\{\begin{array}{l}
1 \text { if } e_{i}=\tilde{z}_{i}-\hat{z}_{i}=0 \\
0 \text { if not }
\end{array}\right.
\end{aligned}
$$

For a good accuracy of this discrete observer, one must use a sampling time small enough and it needs a fast DSP. In the industrial application at GS Maintenance, the clock frequency of DSP is only $150 \mathrm{MHz}$, and it does not allow to work on a small sampling time. So in experimentation an over-sample technique is proposed in the following way: $T_{e-n e w}=\frac{T_{e}}{n}$ with $T_{e}$ is the data acquisition time, $T_{e-n e w}$ is the new computation period, $n$ is the number of over-sample. Considering a differential equation $\dot{X}=f(x)$ :

The explicit Euler's method with a sampling time $T_{e}$ gives: $X(k)=X(k-1)+T_{e} \cdot f(X(k-1))$ with $T_{e}$ is the data acquisition period and computation period too.

With an over sampling time $T_{e-n e w}=\frac{T_{e}}{n}$, the explicit Euler's gives:

$$
\left\{\begin{aligned}
X\left(k T_{e}+\frac{T_{e}}{n}\right) & =X\left(k T_{e}\right)+\frac{T_{e}}{n} \cdot f\left(X\left(k T_{e}\right)\right)+O\left(\frac{T_{e}}{n}\right)^{2} \\
X\left(k T_{e}+2 \frac{T_{e}}{n}\right) & =X\left(k T_{e}\right)+\frac{T_{e}}{n} \cdot f\left(X\left(k T_{e}\right)\right) \\
& +\frac{T_{e}}{n} \cdot f\left(X\left(k T_{e}+\frac{T_{e}}{n}\right)\right) \\
& +2 O\left(\frac{T_{e}}{n}\right)^{2} \\
\ldots & \\
X\left(k T_{e}+T_{e}\right) & =X\left(k T_{e}\right)+\frac{T_{e}}{n} \cdot f\left(X\left(k T_{e}\right)\right) \\
& +\frac{T_{e}}{n} \cdot f\left(X\left(k T_{e}\right)+\frac{T_{e}}{n} \cdot f\left(X \left(k T_{e}\right.\right.\right. \\
& \left.\left.+\frac{T_{e}}{n}\right)\right)+\frac{T_{e}}{n} \cdot f\left(X\left(k T_{e}+2 \frac{T_{e}}{n}\right)\right) \\
& +\cdots+\frac{T_{e}}{n} \cdot f\left(X\left(k T_{e}+(n-1) \frac{T_{e}}{n}\right)\right) \\
& +n O\left(\frac{T_{e}}{n}\right)^{2}
\end{aligned}\right.
$$

Hence it can be remarked that the error is $O\left(T_{e}\right)^{2}$ for a sample time explicit Euler's while for explicit Euler's with an over sampling time, the error is $n O\left(\frac{T_{e}}{n}\right)^{2}$, which reduce 
by $n$ the discretisation error.

In order to reduce again the computation time, one used a table of square root pre-calculated.

\section{Simulation RESUlts}

To verify the effectiveness of the proposed observer, a simulation has been carried out using Matlab/Smulink. The used sampling period is $10^{-4} s$. The simulation results are divided in two part: in one hand the observer is tested under nominal condition (identified parameters), in the other hand the influence of parameters variation is considered (robustness tests). The figures (2,3) illustrate estimated speed and estimated rotor flux. This result present a good performance of the second order sliding mode observer. Error between real speed and estimated speed is very small (0.5\%). An error occurs in the time of changed speed because in the simulation one does not respect the hypothesis constant speed, in experimentation this problem does not appear due to system inertia. The figures $(4,5,6,7)$ prove the robustness of proposed observed with respect to the variation of parameters. In this simulation test, the variation of $\pm 50 \%$ of $R_{s}, \pm 50 \%$ of $R_{r},+20 \%$ of $L_{s},+20 \%$ of $L_{r}$ is considered. The results simulation show that the observer is insensible to $R_{r}, L_{s}$, $L_{r}$ variation. It exists only a small error (1\%) in the case of $\pm 50 \%$ of $R_{s}$.

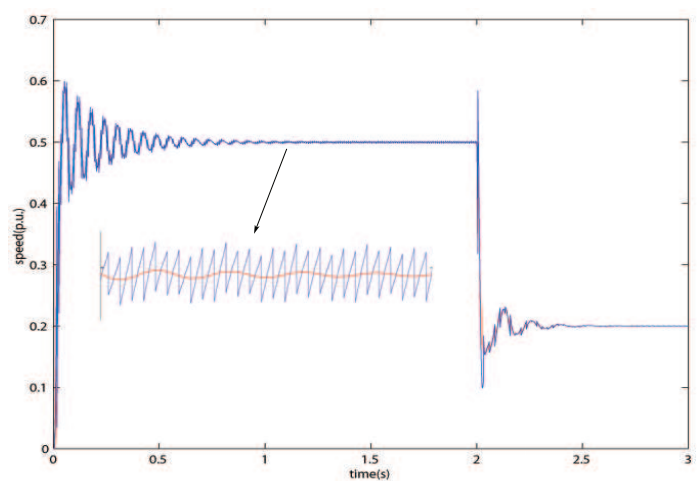

Fig. 2. Estimated speed (blue) and real speed (red).

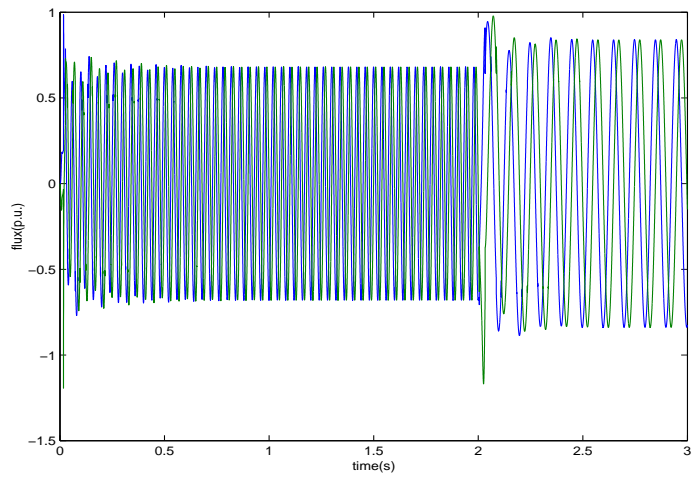

Fig. 3. Estimated rotor flux in the fixed frame.

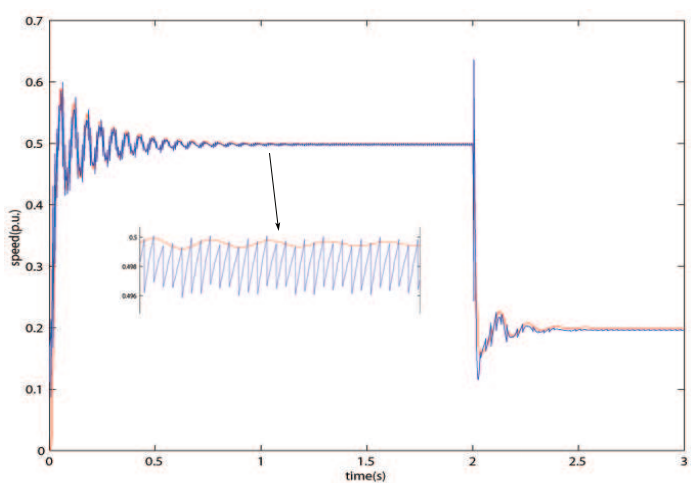

Fig. 4. Estimated speed (blue) and real speed (red) when $R_{s}$ varies $+50 \%$.

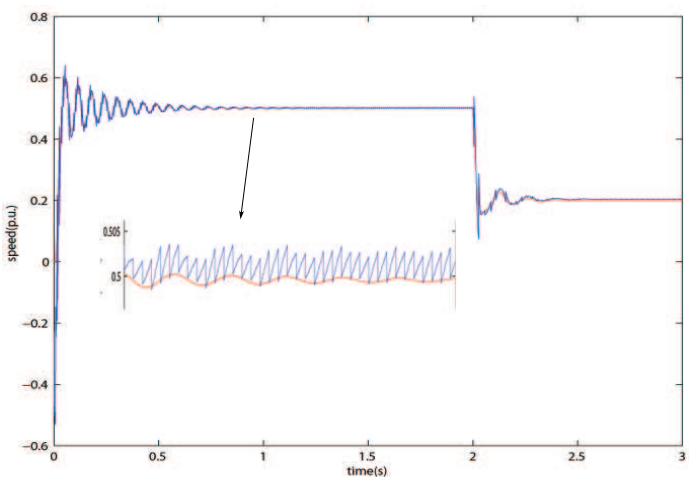

Fig. 5. Estimated speed (blue) and real speed (red) when $R_{s}$ varies $-50 \%$.

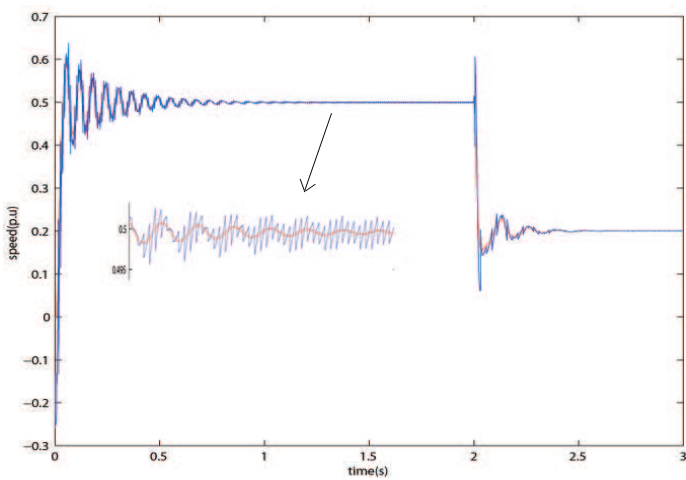

Fig. 6. Estimated speed (blue) and real speed (red) when $R_{r}$ varies $+50 \%$.

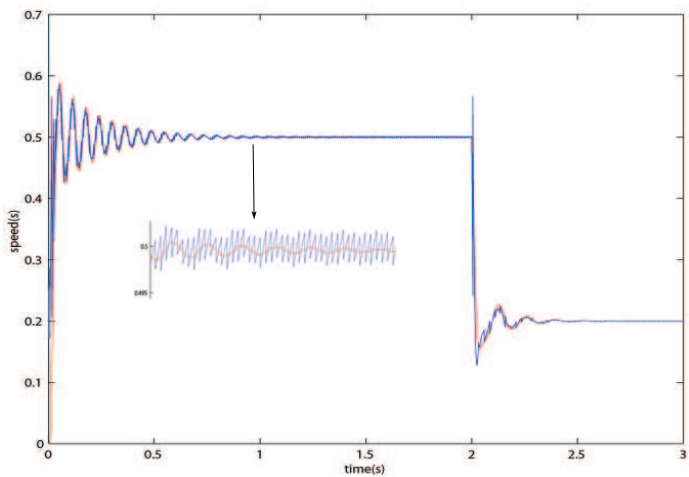

Fig. 7. Estimated speed (blue) and real speed (red) when $R_{r}$ varies $-50 \%$. 


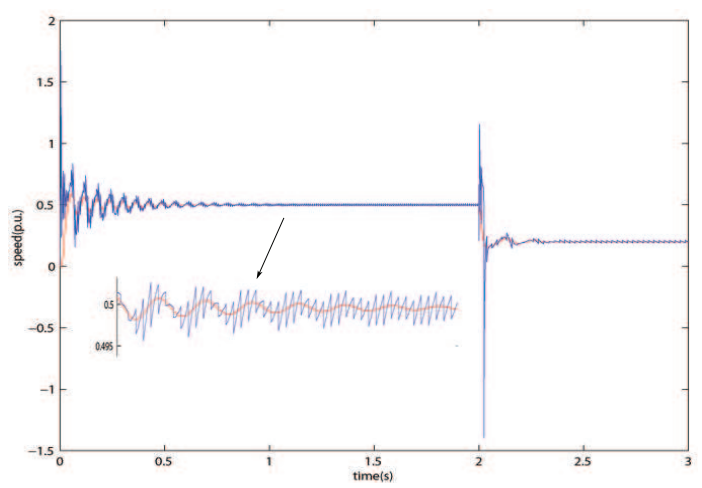

Fig. 8. Estimated speed (blue) and real speed (red) when $L_{s}$ varies $+20 \%$.

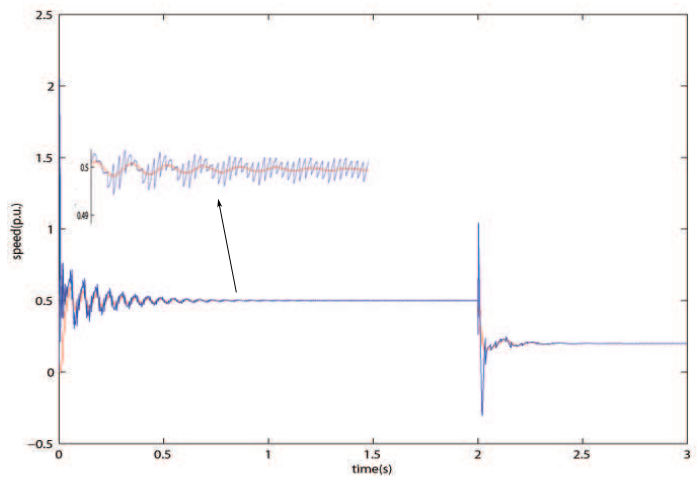

Fig. 9. Estimated speed (blue) and real speed (red) when $L_{r}$ varies $+20 \%$.

\section{EXPERIMENTAL RESULTS}

The proposed second order super twisting sliding mode observer for $I M$ has been implemented at GS Maintenance. The system consists to a $1.1 \mathrm{~kW} / 380 \mathrm{~V} / 50 \mathrm{~Hz}$ induction motor fed by an inverter. The observer is implemented in a single fixed-point TMS320F2812. A mechanical sensor is mounted on the motor's shaft to compare measured speed and estimated speed. At first, the observer has been tested at nominal speed. The figures $(8,9)$ show the estimated speed and rotor flux. In comparison the estimated speed with the real speed which is measured by an encoder, one obtains a good performance of the observer. After that the performance of observer is tested at low speed $(5 \mathrm{~Hz})$ (figure 10). This figure shows a good result of estimated speed. The figure 11 shows that the observer diverges under unobservable condition (very low speed $)^{1}$. To ensure the performance of speed observer, at low speed a speed estimator is proposed and tested ${ }^{2}$. The figure 12 shows under unobservable conditions the observer diverges but the estimator give a satisfactory result. For sum up, our practical approach consists in a variable structure observer: under observability conditions a second order sliding mode observer is used and under unobservable conditions an estimator is used.

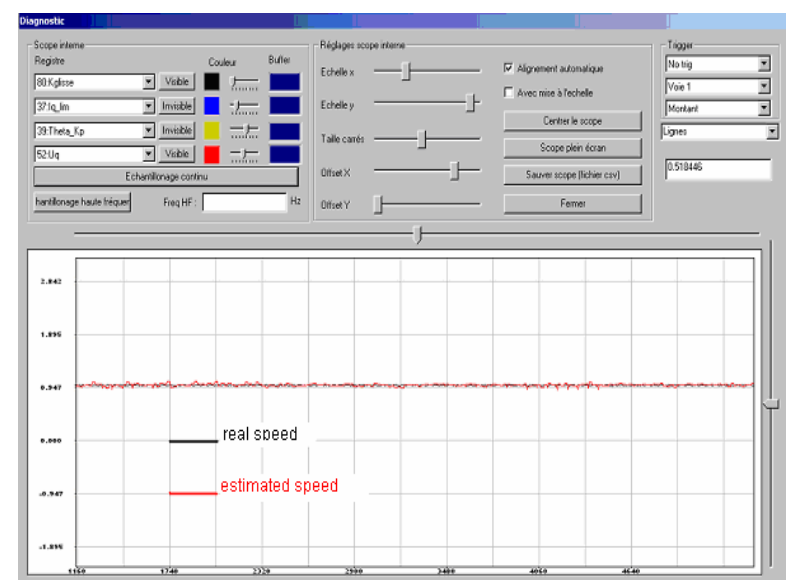

Fig. 10. Estimated speed (red) and real speed (black) at nominal speed (p.u.).

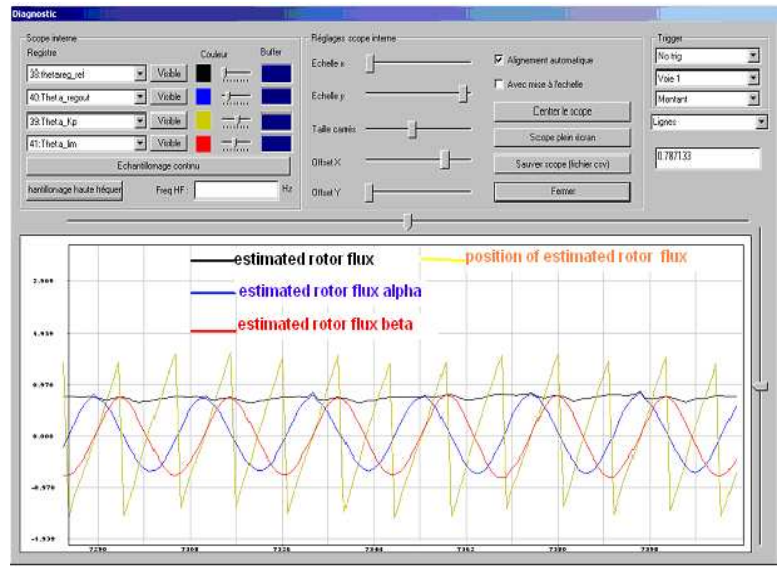

Fig. 11. Estimated rotor fluxes in the fixed frame.

\footnotetext{
${ }^{1}$ see section III for more details

${ }^{2}$ the estimator is simply an integration of normalized motor model
} 


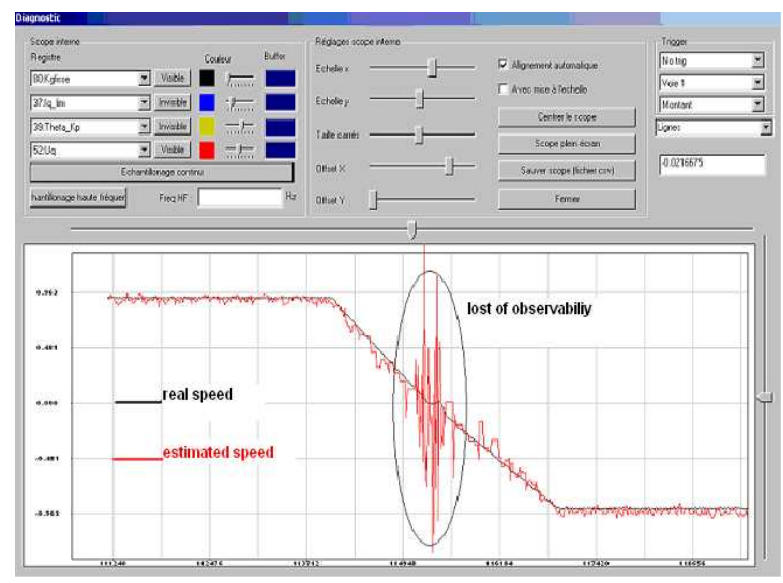

Fig. 12. Estimated speed (blue) and real speed (red) in the dynamic regime (p.u.).

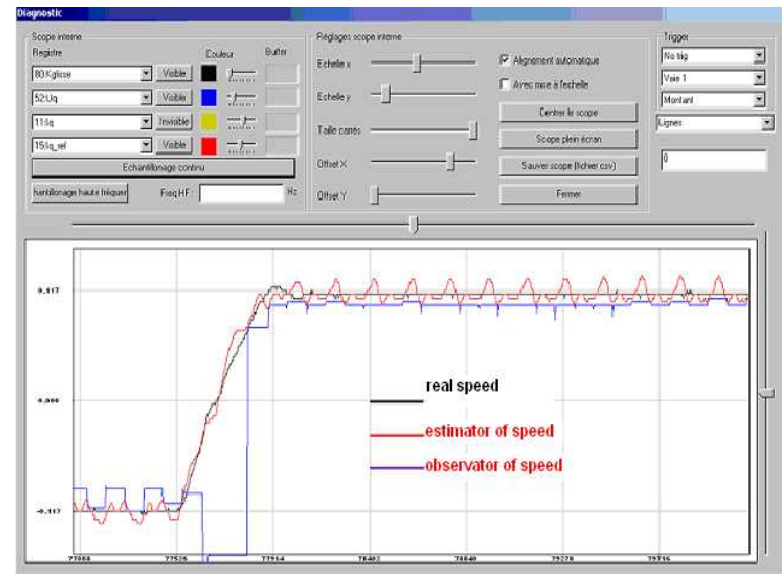

Fig. 13. Speed observer (blue), speed estimator (red) and real speed (black) (p.u.).

\section{CONCLUSION}

In this paper a second order sliding mode observer is designed in order to estimate the speed of $I M$ without mechanical sensor. An industrial application using a usual DSP shows that it is possible to implement a second order sliding mode observer in a single fixed point DSP. The over-sample technique allows to have a very fast sampling with Euler's method. Furthermore, the speed is estimated without the knowledge of load torque. The simulation and experimentation results affirm a good performance of the proposed second order sliding mode observer such that: finite time convergence, robustness with respect to the variation of parameters. The bad behavior of the observer under unobservable conditions (at very low speed) is remedied by using an estimator of speed.

\section{Annexe: Induction Motor data}

\begin{tabular}{|c|c||c|c|}
\hline Rated power & $1.1 \mathrm{~kW}$ & $R_{s}$ & $8.4 \Omega$ \\
\hline Rated speed & $1390 \mathrm{rpm}$ & $R_{r}$ & $5.5 \Omega$ \\
\hline Number of pole pairs & 2 & $L_{s}$ & $0.349 H$ \\
\hline Rated voltage & $220 \mathrm{~V} / 380 \mathrm{~V}$ & $L_{r}$ & $0.349 H$ \\
\hline Rated current & $4.8 \mathrm{~A} / 2.75 \mathrm{~A}$ & $\mathrm{M}_{s r}$ & $0.3 \mathrm{H}$ \\
\hline
\end{tabular}

\section{REFERENCES}

[1] H. Kubota, K. Matsuse and T. Nakano, "DSP-Based Speed Adaptative Flux Observer of Induction Motor" IEEE Transactions on Industry Applications, Vol.29, No.2, pp.344-348, Mar./Apr. 1993.

[2] A. Levant "Robust exact differentiation via sliding mode technique", Automatica Vol 34,No 3,pp 379-384,1998.

[3] G. Bartolini, A. Ferrara and E. Usani, "Chattering Avoidance by Second-Order Sliding Mode Control," IEEE trans. Autom. Cont., Vol. 43, No. 2,pp. 241-246 (1998).

[4] C. Canudas de Wit, A. Youssef, J.P Barbot, Ph. Martin and F. Malrait "Observability conditions of induction motors at low frequencies", 39th IEEE Conference, Vol 3, 2000.

[5] W. Perruquetti and J.P Barbot, "Sliding mode control in engineering", Control Engineering Series.

[6] H. K. Khalil and G. Strangas, "Sensorless Speed Control of Induction Motor", American Control Conference, Boston, Massachusetts, USA, juin 30 - July 2, 2004.

[7] T.M. Wolbank, J.L. Machl and T. Jager, "Combination of signal injection and neural networks for sensorless control of inverter fed induction machines", PESC, Aachen Germany, pp. 2300-2305, 2004.

[8] G.S. Buja "Direct Torque Control of PWM Inverter-Fed AC Motor-A Survey", IEEE Transactions on Industrial Electronics (TIE), Vol.51, NO 4, pp. 744-755, August 2004.

[9] J. Chiasson, Modeling and High-Performance Control of Electric Machines", IEEE Series on Power Engineering, Wiley-Interscience, 2005.

[10] M. Ghanes "Observation et commande de la machine asynchrone sans capteur mcanique",Phd thesis, 2005.

[11] T. Floquet and J.P Barbot, "Super twisting algorithm based stepby-step sliding mode observers for nonlinear systems with unknown inputs", International Journal of Systems Science, Vol 38 , Issue 10 (October 2007).

[12] H. Saadaoui "Contribution la synthse d'observateurs non linaires pour des classes de systmes dynamiques hybrids", Phd thesis, 2007.

[13] I. Boiko, M. I. Castellanos, L. Fridman: Super twisting algorithmbased step-by-step sliding mode observers for nonlinear systems with unknown inputs. Int. J. Systems Science 38(10): 803-815 (2007).

[14] M. Hilairet, F. Auger, and E. Berthelot, Speed and rotor flux estimation of induction machines using a two-stage extended Kalman filterstar, Automatica, Volume 37, Issue 1, January 2009, Pages 107-112.

[15] M. Ghanes and G. Zheng, On Sensorless Induction Motor Drives: Sliding-Mode Observer and Output Feedback Controller" IEEE Transactions on Industrial Electronics (TIE), Vol.56, N9, p. 3404-3413, September 2009.

[16] M. Ghanes, J.P Barbot, J. De Leon, A. Glumineau "A robust output feedback controller for induction motor drivers: new design and experimental validation", International Journal of Control, to appear 2010. 